DOI: https://doi.org/10.47405/mjssh.v6i9.1013

\begin{tabular}{|c|c|}
\hline 4.581 & Malaysian Journal of Social Sciences and Humanities (MJSSH) \\
\hline $\begin{array}{l}\text { Malaysian Journal of } \\
\text { Social cciences and }\end{array}$ & Volume 6, Issue 9, September 2021 \\
\hline (MJ-SSH) & e-ISSN : 2504-8562 \\
\hline & $\begin{array}{l}\text { Journal home page: } \\
\text { www.msocialsciences.com }\end{array}$ \\
\hline
\end{tabular}

\title{
Refugees Life in Malaysia: A Review Paper
}

\author{
Zhooriyati, S. M. ${ }^{1}$, Crendy, T. Y. T. ${ }^{1}$, Aniq Luqman, S. A. ${ }^{1}$, Farah, U. S. ${ }^{1}$, Eunice, D. ${ }^{1}$ \\ 1 Department of Psychology, Faculty of Social Sciences and Liberal Arts, \\ UCSI University Kuala Lumpur
}

Correspondence: Zhooriyati, S. M. (zhooriyati@ucsiuniversity.edu.my)

\begin{abstract}
Refugee crisises have affected nearly every nation in the world. The recent influx of refugees into Malaysia is concerning as the government does not legally acknowledge refugees' legal status. This brings about several questions regarding their survivability in Malaysia, in addition to whether the existing systems and policies are able to accommodate their needs for healthcare, education, and economic opportunity. Although they may have escaped torture and persecution in their own countries, they would still have to face hardships as a refugee in Malaysia. This paper will discuss the life of refugees in Malaysia from the; health, education, economic status, and social life aspects.
\end{abstract}

Keywords: refugees, social life, Malaysia

\section{Introduction}

In many parts of the world, people are being displaced and forced to flee for their lives. In 2018, it was reported that at least 70 million people were forcibly displaced, with many more unaccounted for (United Nations High Commissioner for Refugees (UNHCR), 2019a). Some leave for education, or seeking better jobs and lives, with most escaping life-threatening danger or persecution (Amnesty International, n.d.). Due to conflicts or outright discrimination of religion, ethnicity, or even political opinions and affiliations, these people seek safety and shelter elsewhere. According to the United Nations (UN), there are a few different categories of forcibly displaced persons, being asylum seekers, Internally Displaced People (IDPs), and refugees. Asylum seekers are individuals outside their country of origin, receiving international aid, and are awaiting their refugee status. IDPs are those who are forcibly displaced without crossing an international border. From the 1951 Convention Relating to the Status of Refugees by UNHCR, a refugee is understood to be "a person who is outside his or her country of nationality or habitual residence; has a well-founded fear of being persecuted because of his or her race, religion, nationality, membership of a particular social group or political opinion..."

\section{Literature Review}

There were reported to be around 25.9 million refugees worldwide as of 2018, 500,000 more than was recorded in 2017 (UNHCR, 2019b). From the same report, the prominent origin countries of refugees included the Syrian Arab Republic, Afghanistan, South Sudan, and Myanmar; amounting to 68\% of all refugees in 2017 (Wood, 2019b). Depending on the country's program and policy choices, a displaced person's location of resettlement would eventually be dictated. In most cases, these people tended to 
seek refuge in neighboring nations (UNHCR, 2019; Huang \& Graham, 2019). Refugees from Syria tended to flee to Turkey, Afghan refugees to Pakistan, Myanmar refugees to neighboring countries such as Bangladesh and South East Asia (Human Rights Commission of Pakistan, 2009; Ullah, 2011; Memisoglu \& Ilgit, 2016; Ahmad et al., 2016).

As Malaysia is not a signatory to the 1951 Convention Relating to the Status of Refugees (1951 Convention) and 1967 Protocol Relating to the Status of Refugees (1967 Protocol) which essentially determines the rights and status of refugees (UNHCR, n.d.), the country does not legally acknowledge refugees and their status. Consequently, refugees in Malaysia are considered to be illegal immigrants (UNHCR, n.d.; Immigration Act 1959/63, 2006). This brings about several issues with regards to refugees' rights and safeguards from exploitations. Furthermore, the Malaysian government does not approve the UNHCR cards to be an official state document that permits refugees to get formal education or legal work (Ahmad et. al., 2018; Eid and Rokis, 2019). As a result, refugees are forced to be self-supporting when it comes to health and survival (Kuak Kok et al., 2013).

In spite of this, Malaysia has been known to permit refuge until they are repatriated or resettled to another country. As of January 2018, Malaysia was reported to be home to the highest number of refugees in South East Asia (UNHCR, 2019). As of January 2021, there are 178,140 refugees and asylum seekers in Malaysia, with the majority residing in Selangor $(66,030)$, Kuala Lumpur $(27,370)$, and Penang $(18,660)$, and the least in Putrajaya (450) and Perlis (280) (UNHCR, n.d.). More than half are from Myanmar, many of whom are Rohingya refugees (UNHCR, 2018). This paper will, therefore, peruse over several elements of the state of refugees in Malaysia. The selected aspects include health, education, economic status, and social life.

\section{Health}

It is common among refugees to not have access to healthcare in their host country due to their legal status and financial ability (World Health Organization (WHO), 2010). Fortunately, in 2015, the Ministry of Health in Malaysia signed a Memorandum of Understanding (MoU) with UNHCR to allow refugees access to public healthcare facilities with half of the foreigners' payment rate (Wake \& Cheung, 2016). Even with the discount by the government, the cost is still considered high for the refugees and thus healthcare is still considered to be relatively inaccessible for some (Letchamanan, 2013). Despite the deprivation to medical help due to their financial difficulties, refugees emphasized that the healthcare services are easily accessible and they trust that Malaysia's healthcare can meet their range of demands (Chuah et al., 2018).

Chuah et al. (2018) found that the health concerns of the refugees range from contagious to noncontagious diseases and malnutrition. In 2015, the UNHCR reported that $23.9 \%$ of the adult refugees in Malaysia had hypertension and 8\% had diabetes, while Amara and Aljunid (2014) stated that 7\% of the same population had cardiovascular diseases. Malnutrition is a major concern among children refugees (Chuah et al., 2018). It was reported that $27.5 \%$ of them were underweight and $11.5 \%$ stunted (Teng \& Zalilah , 2011). Apart from physical health issues, these refugees experienced various mental health conditions caused by "trauma, discrimination, uncertainties of their future, and socio-economic circumstances they are faced with" (Low et al., 2014).

Tay et al. (2020) identified that $43 \%$ of the Myanmar refugees living in Kuala Lumpur suffer from at least one mental disorder, namely depression, generalized anxiety disorder (GAD), post-traumatic stress disorder (PTSD), and complicated grief, attributed to past trauma, pre and postmigration living difficulties, and adaptive stressors. These results are supported by the finding of Kaur et al. (2020), who identified the prevalence of mental health disorders among Rohingya refugees in Selangor to be $32.3 \%$ suffering from major depressive disorder (MDD), $41.8 \%$ from GAD, and 38.2\% from PTSD. Further, Kaur et al. discovered that presentations of these disorders could be exacerbated by refugees' exposure to physical injury, violence, and trauma; new refugees' period of financial and social adjustment; lack of social support; and the psychological distress experienced due to food insecurity and physiological consequences of food deprivation. Similarly, a study conducted among the Dari- and 
Arabic-speaking refugee community in Kuala Lumpur by Shaw et al. (2018) identified that $98.8 \%$ reported high levels of distress, presenting with symptoms of depression, anxiety, and trauma.

In order to get treatment from public healthcare facilities, one needs to own a legal identification document (Institute of Human Rights and Peace Studies (IHRP), 2014). Refugees are required to show their UNHCR card if they want to get medical treatment or consultation in a public medical facility. The Health Equity Initiative (Verghis, 2014) revealed that there were reports of asylum seekers ratted out on to the authorities for getting medical help at the General Hospital of Kuala Lumpur. These requirements and events have either directly or indirectly discouraged refugees from seeking medical help from the public hospitals or clinics as they are afraid of being arrested (IHRP, 2014). On the contrary, private health facilities are easier to access as these private institutions do not require the refugees' legal documents (Wahab, 2017). Unfortunately, most refugees are financially unable to get treatment at private clinics or hospitals as the costs are even higher than public healthcare.

In 2014, a health insurance program named REMEDI was established to improve refugees' access to health care facilities (Chuah et al., 2018). This program was a collaboration between UNHCR and a private insurance company. A program like this has shown potential in reducing the financial barriers in accessing healthcare. Although the refugees are given financial support by REMEDI, there are other obstacles that hinder them from accessing healthcare. The cultural and language variances between the refugees and Malaysia is one of it (UN, 2013). Not to forget, the legal status and low health literacy also contribute to the refugees' hardships in getting proper medical management (Chuah et al., 2018). Chuah et al. also highlighted that refugees are at times not aware of the services available to them, especially new refugees, and are also not aware of their rights to healthcare, which consequently prevents them from seeking help.

In contrast, Chuah et al., (2019, as cited in Nungsari et al., 2020, p.7) reported that many refugees perceived the Malaysian healthcare system and facilities to be of quality and highly available despite complaints about its affordability. However, the refugees interviewed by Nungsari et al. (2020) pointed out that the response received from healthcare providers vary based on refugee's ability to communicate, thus influencing their perception of the quality of Malaysian healthcare. For example, one refugee explained that hospital staff treat refugees who are able to converse in English or the Malay language politely, while those who are not able to are insulted.

Despite the recommendation from the UN Committee on the Rights of the Child (2007) that "children without official documentation should be allowed to access basic services, such as health and education while waiting to be properly registered", many child refugees and asylum seekers were denied services at healthcare facilities (IHRP, 2014). It was also found that unregistered pregnant refugees were reported to the higher-ups after they had given birth, even after they had paid the hospital fees (Verghis, 2014). Mothers who gave birth in government hospitals also risk being detained with their new born babies (High et al., 2014). The human rights of the children and women of the group are being deprived, which will only further discourage them from seeking medical care.

Although private bodies, refugee agencies, non-governmental organizations (NGOs), and civil society organizations (CSOs) in Malaysia provide aid in terms of more affordable or free healthcare services, transportation, interpreters to overcome language barriers, and by accepting those without legal identification, there are still areas of need that are yet to be addressed (Yunus et al., 2021). Yunus et al. identified a lack in services of promotive and preventive health programs; secondary and tertiary healthcare services; specialized services for mental health, reproductive health, or dental care; as well as inadequate follow-ups and management of chronic diseases due to inconsistent services. They also stated that the health services available are mainly offered in states with a higher population of refugees such as in the Klang Valley, Penang, Negeri Sembilan, and Johor, while those in the less populated and underdeveloped states (Kedah, Terengganu, Pahang, Kelantan, Perak, and Perlis) are not provided with or have limited access to adequate healthcare services. 


\section{Education}

Limited access to education is one of the main concerns for refugees in Malaysia besides healthcare (Kuak Kok et al., 2013; Letchamanan, 2013). A report by UNHCR in 2015 stated that only 30\% of refugee children have access to any form of education. According to Eid and Rokis (2019), there are several barriers that restrict refugees from accessing formal education, namely, legal restriction, economics, institutional, and parental language barriers, along with subpar learning environment and discrimination. As a result, refugees often go on for decades without proper basic education (Letchamanan, 2013). Children suffer the most, as survival and basic needs take precedence over education, which heavily impact their behavior and cognitive abilities, especially in early education (Eid \& Rokis, 2019).

Children born in Malaysia, to their refugee parents, do not obtain a birthright citizenship or 'jus soli', therefore are also considered stateless (Palik, 2020). Due to their legal status, public schools are not an option for these children. Refugees and migrants have limited to no access to public schools, and most cannot afford to bear the cost of attending private schools (The Equal Rights Trust, 2014). Instead, refugee children who are fortunate enough to learn would receive their basic education from community-run learning centers, sometimes supported by the UNHCR, local NGOs, and private donors (Letchamanan, 2013; Wake \& Cheung, 2016). As of 2020, there were around 148 such learning centers in Malaysia (Palik, 2020).

These centers would charge between RM20 to RM50, per child per month. Thus causing issues for families with multiple children as the cost of transportation, school fees, food, and learning materials add up to become unbearable financial burden. Consequently, these children resort to dropping out, as they no longer can afford it (Wahab, 2017). Therefore, it is of utmost importance for the parents to maintain their source of income, in any form, to support their children's education in Malaysia.

Forced to be self-supporting, the teachers at community-run learning centers tend to be refugees themselves. This essentially puts the teachers' psychosocial wellbeing at risk as they too have gone through hardships and conflicts (Letchamanan, 2013; Tay et al., 2019). However, Kok et al. (2013) discovered that teachers are happy to work and teach for the good of the children's future; that they are proud of their work and believe that it would contribute to the greater good of the community. The refugee teachers are university graduates from their home country who were driven to teach. They saw great value in teaching their mother language, English, and other core subjects, as it ensured that the children would be able to continue with their education back in their own country or if relocated to other countries (Kok et al., 2013). The notion of shame and honorability supersedes the fact that some teachers would go unpaid, as they are not registered with the UNHCR. In this case, the community would at times split their monthly payment with those who are unpaid (Kok et al., 2013).

These learning centers are a far cry from formal schools, with sufficient resources and conducive learning environments. Instead, more often than not, these learning centers are either flats or houses that have been converted to serve as rudimentary classrooms. Often ill-equipped with sufficient educational resources, it contributes to the increased difficulty in providing quality education (Eid \& Rokis, 2019). An alternative to community-funded learning centers are religious schools, also known as 'madrassas'. This alternative attracts refugee parents in Malaysia who push their children to gain religious education or those who believe that this is the only form of education available for their children (Wake \& Cheung, 2016).

Palik (2020) stated that the Ministry of Education (MoE) recognized community-based organizations (CBO) as 'alternative education centers', on par to private schools. $70 \%$ of refuge children attend CBOs to obtain non-formal education. Most of these learning centers have adopted the Malaysian national syllabus though with no official recognition of study and certification of learning (Rahman, 2011; UN Refugee Agency, 2011). A child's future is in great jeopardy as they would not possess any officially recognized education, which would result in greater hardship when seeking for jobs in the future. 
Palik (2020) highlighted some problems faced by teachers at CBO schools. As teachers in these organizations are often either Malaysian volunteers or Rohingya teachers, they lack the necessary pedagogical training, resulting in the "quality of education to vary across subjects" (p.3). Some teachers also find it challenging to teach the children, while others find it difficult to manage the workload, leading to high turnover. Next, a collaborative parent-teacher relationship is lacking, as parents are unwilling to communicate with the teachers without compensation of food or money. Finally, due to their cultural, religious, and financial conditions, parents do not allow their older children to seek an education. Boys are sent to work, while girls are kept at home as parents disagree with the co-ed nature of the organizations or to help out with housework, while some are married off early to ease the family's financial burden (Palik, 2020).

An interview by Farzana et al. (2020) with the headmaster of a Rohingya community primary school, highlighted that refugee children do not have access to secondary level education. He also stated that only a small number of children attend school largely due financial constraints and the location of the school. He explained that parents hesitate to leave their home in rural areas to send their children to schools mostly located in the city, for fears of being caught by the authorities. Furthermore, some parents do not possess any means of transportation, and neither have the time or money to spare for it.

In efforts to improve the out-of-school refugee and internally displaced children's access to quality primary education and to support their retention once enrolled, the UNHCR's Educate a Child Programme (EAC) from 2015 to 2019, was implemented in Malaysia (UNHCR-EAC, 2019). Although not common, thanks to the MoU signed by UNHCR with several universities, namely, University of Nottingham, International University of Malaya-Wales, Limkokwing University of Creative Technology, Brickfields Asia College, International Innovative College, and HELP University, refugee children have been provided an opportunity to receive higher education by accessing tertiary education courses (UNHCR, n.d.). However, even with this opportunity, students still faced discrimination (Britwell, 2019).

\section{Economic Status}

According to the Human Rights Watch (2000), the Malaysian government provided some refugees with six-month work permits due to the influx of refugees in Malaysia in 1990. However, these permits were non-renewable and no work permit for refugees were successfully implemented ever since (Wake, 2016). The government had taken this stance to prevent more refugees from entering Malaysia by using 'better working opportunities' as a reason, as well as to prevent security issues and additional costs that would arise from the increase of refugees (Yasmin, 2019).

These days, refugees are not legally allowed to work in Malaysia, but some do receive assistance (Wake, 2016). However, the number of refugees who do not receive support is high, reportedly at $92 \%$ (International Rescue Committee, as cited in Smith, 2012). Fortunately, the UNHCR continuously fought for work permits for the refugees in Malaysia (UNHCR, 2016), resulting in the Malaysian government forming a high-level governmental committee to discuss this issue (Lokman, 2016).

That said, refugees still make their living by working informally (Todd et al., 2019), even at the risk of facing legal repercussions under domestic laws, such as Immigration Act 1959/63, Employment Act 1995 and Companies Act 1965 (Wahab, 2017). Wake and Cheung (2016) revealed that most refugees have to take up jobs that are physically challenging, dangerous, and usually based on short term contracts, such as, shopkeepers, cleaners, helpers, construction workers, waiters, odd job workers, refugee school teachers, community workers, self-employed, and so on. It was also found that they have to change jobs 2 to 6 times over the period of them being in Malaysia (Wake \& Cheung, 2016).

Wahab (2017) stated that despite refugees earning a living by working challenging jobs, they earn low salaries. Some of them earn less than the minimum wage of RM1000 set by the government in 2016 . Wahab also discovered that some self-employed refugees rented trading licenses from local traders to run their businesses as they are not legally allowed to apply for license to own businesses, while others received financial assistance from NGO microfinance facilities or from family and friends to set up 
their businesses. These self-employed refugees then help their fellow refugees by offering them jobs and goods (Wahab, 2017). The economic and financial hardships they encountered had led to several other issues, mainly in health (Chuah et al., 2018) and education (Letchamanan, 2013).

Wahab (2017) identified that $64.6 \%$ of their interviewed refugees were unemployed. These refugees were new in Malaysia, thus did not own any legal documentation and were unable to converse fluently in the Malaysian national language, which contributed to their unemployment. Although the Malaysian government does not consider the UNHCR cards as official state document that permit access to formal education or legal work (Ahmad et. al., 2018), it was found that it is easier for the refugees to get a job if they owned one (Wake, 2016). Therefore, not only is the UNHCR card important for refugees to be legally accounted for, it also gives them an upper hand at securing a job.

A study conducted by Nungsari et al. (2020) among a sample of Rohingya refugee construction workers, found that although this type of job pays them above minimum wage (an average of RM 1400), they still faced many financial commitments and challenges. As one refugee highlighted, their pay is not enough to support them and their families. As sole breadwinners, they needed to remit their incomes to their families back in their home countries. Besides that, for refugees who have housing, their rent takes up their income as well. In this study, some refugees pay an average of RM300 as their monthly rental, while others are provided with accommodation by their employers as payment-in-kind. Refugees also stated that they lose money from paying fines or bribes to law enforcement officers if they are caught, to avoid being jailed, even when carrying their UNHCR documentations. They would rather "settle" matters with the officers on the streets, which would cost them RM100 to RM200, compared to paying fines ranging from RM2000 to RM3000 at the police station.

Refugees also spent their earnings to pay for their children's education, transportation, meals; administrative and travel expenditure relating to their registration of refugee status and interview for resettlement with the UNHCR and other government agencies; financial contributions to their faithbase and welfare activities in their community; and for healthcare treatments (Wahab, 2017). All these factors result in the refugees in Malaysia facing poverty (Nah, 2010).

\section{Social Life}

Refugees' decision to come to Malaysia is strongly influenced by the presence of relatives in the country (Wake \& Cheung, 2016). The social network that was established with their acquaintances before they reached Malaysia was important to create a foundation in Malaysia such as finding jobs and a place to stay. Wake and Cheung found that the refugees are more likely to live together with their community, as they are able to divide their cost of living by sharing homes.

However, communal living has its disadvantages. Families are confined to crowded houses, while children are forbidden from playing outdoors like other normal children due to the lack of play equipments (Kok et al., 2016), and parents' fear that they might be caught by authorities when playing outside their homes (High et al., 2014). Nah (2019) stated that there are two types of living space for refugees in Malaysia, jungle sites and urban sites. Jungle sites refer to "plantations or pockets of jungle scattered in and around urban areas" (p.1). Refugees here live in huts or just sleep in the jungle. While those in the urban sites live in run-down and densely populated buildings, to save on rental costs. Refugees in the jungle sites lack supply of clean water and sanitation, thus increasing the risk of diseases, while those in the urban sites are more vulnerable to sexual and/or physical exploitation and exposed to infectious diseases due to overcrowding Nah (2019).

Social life of teenage refugees differ from their Malaysian counterparts, as $70 \%$ of refugee children do not have proper access to education (UNHCR, 2015b) and are forced to work upon arrival in Malaysia (Iskhandar, 2015). Kok et al. (2016) found that teenage refugees face three major challenges, being financial, social, and academic. Still, they would rather work than seek education. However, their fear of being caught by the authorities and their inability to seek justice for crimes committed against them adds to their distress. Thus, Kok et al. identified that these teenage refugees cope with their problems by seeking help from their social circles (family and friends), teachers, and God. 
Low et al. (2014) stated that as refugees do not own any legal identification, they tend to live in constant fear of being caught by the authorities. They were more likely to be discriminated by the locals, such as being charged higher rents, denied their salaries, and, being bullied and exploited. Low et al. explained that, due to these social discriminations, refugees are at greater danger of experiencing psychological consequences of helplessness, fearfulness, and distress, resulting in increased health and psychological problems. However, this is contradicted by Wake and Cheung's (2016) findings, which suggest that the refugees have a positive relationship with the local communities.

Refugees' belief in their culture has a huge influence on their social life in their host countries (Smith, 2013). Wake and Cheung (2016) concluded that the loose connections of the refugees with their cultural background brought them closer to the locals, which improved their social life in Malaysia. On the other hand, their relationship with their own community is improved by attending religious, welfare, and community activities (Wahab, 2017). These community functions aided them to further expand and strengthen their social networks. In addition, the refugees in the study by Low et al. (2014) emphasized that their strong community bond and ethnic identification with their own people empowered them to deal with the social discrimination and psychological distress faced, more positively. Their will to provide their families in Malaysia and their home country a better life also helped them to overcome their hardships.

Fortunately, there are CBOs that are established by the refugees to support one another (Wake \& Cheung, 2016). Although they are not registered nor funded, these organizations aim to help the refugees in many aspects such as documentation, education, and livelihood support. These CBOs are financially unstable as they are dependent on the membership fees and donations (Wake \& Cheung, 2016). Therefore, the amount of aid they provide refugees are limited (Wake, 2016). Still, these CBOs are a source of protection for refugees who are not provided full protection by the Malaysian government (Wahab, 2017).

\section{Conclusion}

The refugee situation in Malaysia is not necessarily a dire one. The basic wellbeing of the refugees is being taken care of one way or another, either by the government or NGOs. Parallel to Malaysia's general doctrine of neutrality, the government does not take part or choose sides in any international conflict or circumstances such as the proliferation of immigrants (Farzana \& Haq, 2019). However, Malaysia has stepped out of its stance and called out Myanmar for its treatment on Rohingyas ( $\mathrm{Ng}$, 2016). Regardless, the situation in regards to refugees in Malaysia ought to be viewed on a humanitarian basis, along with it being an international obligation of the nation. With recent events such as the Covid-19 pandemic, more has been uncovered of the reality of refugees in Malaysia. Malaysians are enlightened of the harsh living conditions that refugees and asylum-seekers are living in (Azmi et al., 2019; Bedi, 2020). Now, more than ever, it is important to ensure the wellbeing of refugees and asylum-seekers in Malaysia. Due to their living environment, limited access to decent healthcare, and low health literacy, these groups of people are especially at risk and vulnerable to the spread of diseases.

Several prevalent issues that were discovered within the healthcare, educational, social, and economic sectors all influence the wellbeing of refugees in Malaysia. Limited access to healthcare due to financial issues and low health literacy inhibits refugees in getting medical aid in the first place. In the education sector, refugee children have no access to official academic institutions. Consequently, they would rely on community-run learning centers in order to get any form of education. Economically, refugees are having a hard time supporting themselves and family due to low-paying jobs, not to mention the legality of the entire process. One main takeaway is the heavy dependence of refugees on their own community. The importance of the refugees' network and community support plays a prominent role in whether or not they will have a job, a place to learn, and even relative social stability. As the Malaysian government tries its best in safeguarding the refugees without 
compromising the welfare of the people, refugees look toward their community in order to survive the harsh reality of the world.

\section{References}

Amara, A. H., \& Aljunid, S. M. (2014). Noncommunicable diseases among urban refugees and asylum-seekers in developing countries: a neglected health care need. Globalization and Health, 10(1), 24.

Amnesty International. (n.d.). Key facts about refugees and asylum seekers' rights. https://www.amnesty.org/en/what-we-do/refugees-asylum-seekers-and-migrants/

Azmi, N. F., Ruslee, S. N., Harumain, Y. S., Kamaruzzaman, S. N., Chua, S. J. L., \& Au-Yong, C. P. (2019). A study of overcrowding factors in public low-cost housing in Malaysia. Journal of Building Performance, 10(1).

Bedi, R. (2020, March 22). NGO: Include undocumented migrant workers and refugees in Covid-19 response plan. The Star. https://www.thestar.com.my/news/focus/2020/03/22/ngo-includeundocumented-migrant-workers-and-refugees-in-covid-19-response-plan

Britwell, J. J. (2019). Understanding education and understanding yourself as a refugee learner seeking access to higher education in Malaysia: Insights from a pilot study. Cambridge Open-Review Educational Research e-Journal, 6, 180-194

Chuah, F. L. H., Tan, S. T., Yeo, J., \& Legido-Quigley, H. (2018). The health needs and access barriers among refugees and asylum-seekers in Malaysia: A qualitative study. International Journal for Equity in Health, 17(1), 120.

Committee on the Rights of the Child. (2007). Concluding Observations, Malaysia, UN Doc. $\mathrm{CRC} / \mathrm{C} / \mathrm{MYS} / \mathrm{CO} / 1$.

Eid, I., \& Rokis, R. (2019). The barriers to education among the Palestinian refugee children in Malaysia. Journal Of Islam In Asia, 16(2).

Farzana, K. F., Pero, S. D. M., \& Othman, M. F. (2020). The dream's door: Educational marginalization of Rohingya children in Malaysia. South Asian Journal of Business and Management Cases, 9(2), 237-246. doi: 10.1177/2277977920905819

Farzana, K., \& Haq, M. (2019). Malaysia's political orientation in diplomatic neutrality. Intellectual $\begin{array}{lll}\text { Discourse, } & \text { Special 783-798. }\end{array}$ https://search.proquest.com/openview/25224c5e469522b320863f30c13d5211/1?pqorigsite $=$ gscholar $\& \mathrm{cbl}=826340$

High, H., Cowlishaw, G., Missbach, A., Ramsay, G., Hoffstaedter, G., \& Lee, H. (2014). National inquiry into children in immigration detention 2014: A submission from the Australian anthropological society. Australian Human Rights Commission. https://www.waunet.org/downloads/wcaa/submissions/children_detention.pdf

Huang, C., \& Graham, J. (2019). Where do internally displaced people live and what does that mean for their economic integration?. Center of Global Development Brief https://www.cgdev.org/publication/where-do-internally-displaced-people-live-and-what-doesmean-their-economic-integration

Human Rights Commission of Pakistan. (2009). Afghan refugees in Pakistan: Push comes to shove [Ebook]. Human Rights Commission of Pakistan. http://www.operationspaix.net/DATA/DOCUMENT/4816 v Afghan_Refugees_in_Pakistan_ P

Human Rights Watch. (2000). Living in limbo: Burmese rohingyas in Malaysia, 12(4). https://www.hrw.org/reports/2000/malaysia/index.htm\#TopOfPage.

Iskhandar, R. (2015, June 29). Thousands of Myanmar refugees, asylum seekers stuck in Malaysian poverty cycle. ABC News. http://www.abc.net.au/news/2015-06-29/thousands-of-refugeesstuck-in-malaysian-poverty-cycle/6575134

Kaur, K., Sulaiman, A. H., Yoon, C. K., Hashim, A. H., Kaur, M., Hui, K. O., Sabki, Z. A.,

Francis, B., Singh, S., \& Gill, J. S. (2020). Elucidating mental health disorders among Rohingya refugees: A Malaysian perspective. International Journal of Environmental Research and Public Health, 17(18), 6730. doi: 10.3390/ijerph17186730 
Kok, J. K., Lee, M. N., \& Low, S. K. (2016). Coping abilities and social support of Myanmar teenage refugees in Malaysia. Vulnerable Children and Youth Studies, 12(1), 71-80. doi:10.1080/17450128.2016.1263774

Kok, J. K., Low, S. K., \& Lee, W. Y. (2013). Dreams and participation in education: A narrative inquiries into the life experience of Myanmar refugees in Malaysia. Journal of Advanced Social Research, 3(2), 79-92.

Letchamanan, H. (2013). Myanmar's Rohingya refugees in Malaysia: Education and the way forward. Journal of International And Comparative Education, 2(2), 86-97. doi: 10.14425/00.50.24

Lokman, T. (2016, June 22) Nur Jazlan warns UNHCR: Do not blackmail Malaysia. New Straits Times. http://www.nst.com.my/news/2016/06/153628/nur-jazlanwarns-unhcr-do-not-blackmailmalaysia.

Low, S. K., Kok, J. K., \& Lee, W. Y. (2014). Perceived discrimination and psychological distress of Myanmar refugees in Malaysia. International Journal of Social Science and Humanity, 4(3). doi: 10.7763/IJSSH.2014.V4.346

Memisoglu, F., \& Ilgit, A. (2016). Syrian refugees in Turkey: Multifaceted challenges, diverse players and ambiguous policies. Mediterranean Politics, 22(3), 317-338. doi: $10.1080 / 13629395.2016 .1189479$

Nah, A. M. (2010). Refugees and space in urban areas in Malaysia. Forced Migration Review, (34), 29. https://www.alnap.org/system/files/content/resource/files/main/nah-refugees-and-space-inurban-areas-in-malaysia.pdf

Ng, E. (2016, December 4). Malaysia's prime minister leads protest against 'genocide' against Muslim in Rohingya. Independent. https://www.independent.co.uk/news/world/genocide-of-rohingyaburma-aung-san-suu-kyi-malaysian-pm-najib-razak-leads-protest-against-a7454656.html

Nungsari, M., Flanders, S., \& Chuah, H. Y. (2020). Poverty and precarious employment: The

case of Rohingya refugee construction workers in Peninsular Malaysia. Humanities and Social Sciences Communications, 7(1), 1-11. https://doi.org/10.1057/s41599-020-00606-8

Palik, J. (2020). Education for Rohingya refugee children in Malaysia. Peace Research Institute Oslo (PRIO) Policy Brief, 2. https://resourcecentre.savethechildren.net/node/17626/pdf/palik_julia__education_for_rohingya_refugee_children_in_malaysia_prio_policy_brief_2-2020.pdf

Rahman, J. (2011). Access to Education for Children under the Protection of the United Nations High Commissioner for Refugees (UNHCR): Case Study in Kuala Lumpur, Malaysia.

Shaw, S. A., Pillai, V., \& Ward, K. P. (2018). Assessing mental health and service needs among refugees in Malaysia. International Journal of Social Welfare. doi:10.1111/ijsw.12313

Smith, L. (2013). Female refugee networks: Rebuilding post-conflict identity. International Journal of Intercultural Relations, 37(1).

Tay, A. K., Mohsin, M., Hau, K. M., Badrudduza, M., Balasundaram, S., Morgan, K., Parthiban,

N., \& Silove, D. (2020). Variations in prevalence and risk profiles for common mental disorders amongst Rohingya, Chin and Kachin refugees from Myanmar. Psychol Med, 11, 1-15. doi: 10.1017/S0033291720003104

Tay, K., Ong, A., Pheh, K., Low, S., Tan, C., \& Low, P. (2019). Assessing the effectiveness of a mental health literacy programme for refugee teachers in Malaysia. Malaysian Journal of Medical Sciences, 26(6), 120-126. doi: 10.21315/mjms2019.26.6.12

Teng, T. S., \& Zalilah, M. S. (2011). Nutritional status of Rohingya children in Kuala Lumpur. Malaysian J Med Heal Sci, 7(1), 41-9.

Todd, L., Amirullah, A., \& Shin, W. Y. (2019). The economic impact of granting refugees in Malaysia the right to work. Policy Ideas NO. 60. https://www.tent.org/wpcontent/uploads/2019/08/IDEAS-Malaysia.pdf

Immigration Act 1959/63. (2006). Laws of Malaysia, Act 155. The Commissioner of Law Revision

The Equal Rights Trust. (2014). Equal only in name: The human rights of stateless Rohingya in Malaysia. The Equal Rights Trust.

Ullah, A. (2011). Rohingya refugees to Bangladesh: Historical exclusions and contemporary marginalization. Journal of Immigrant \& Refugee Studies, 9(2), 139-161. doi: $10.1080 / 15562948.2011 .567149$

UN Refugee Agency. (2011). Refugee education: A global review. UNHCR.

UNHCR. (2011). The 1951 Convention Relating to The Status of Refugees and its 1967 Protocol. https://www.unhcr.org/4ec262df9.pdf 
UNHCR. (2015). Education. http://www.unhcr.org.my/Education-@-Education.aspx.

UNHCR. (2016, June 21). UNHCR rolls out new card.

http://www.unhcr.org.my/News_Views-@_UNHCRMalaysiaNewCard.aspx.

UNHCR. (2019). Global Trends: Forced Displacement in 2018. https://www.unhcr.org/5d08d7ee7.pdf

UNHCR. (2019, June 19). Worldwide displacement tops 70 million, UN Refugee Chief urges greater solidarity in response. https://www.unhcr.org/en-my/news/press/2019/6/5d03b22b4/worldwidedisplacement-tops-70-million-un-refugee-chief-urges-greater-solidarity.html

UNHCR. Global Appeal 2012-2013 - Malaysia (n.d). https://www.unhcr.org/enmy/publications/fundraising/4ec23106b/unhcr-global-appeal-2012-2013-malaysia.html

UNHCR. (n.d.). Figures at a glance in Malaysia. https://www.unhcr.org/en-my/figures-at-a-glance-inmalaysia.html

UNHCR. (n.d.). Education in Malaysia. https://www.unhcr.org/en-my/education-in-malaysia.html

UNHCR- EAC. (2019). 2015-2019 - End of project report UNHCR - Educate a child programme. UNHCR. https://www.unhcr.org/5fa2d1977.pdf

United Nations. (1989). Convention and protocol relating to the status of refugees. Annual Review of Population Law, 16, 175.

United Nations. General Assembly, \& Grover, A. (2013). Report of the Special Rapporteur on the Right of Everyone to the Enjoyment of the Highest Attainable Standard of Physical and Mental Health: Addendum: Mission to Japan (15-26 November 2012). United Nations General Assembly.

Verghis, S. (2014). Stop the arrest and detention of asylum seeking women accessing maternal health care. Aliran. https://aliran.com/civil-society-voices/2014-civil-society-voices/stop-arrestdetention-asylum-seeking-women-accessing-maternal-health-care/

Wahab, A. AB. (2017). Rethinking refugees as economically isolated: The Rohingyas participation in informal economy in Klang Valley, Malaysia. JAS (Journal Of ASEAN Studies), 5(2), 102. doi: $10.21512 /$ jas.v5i2.3664

Wake, C. (2016). 'Turning a blind eye' The policy response to Rohingya refugees in Malaysia. Humanitarian Policy Group.

Wake, C., \& Cheung, T. (2016). Livelihood strategies of Rohingya refugees in Malaysia 'We want to live in dignity'. Overseas Development Institute.

Wood, J. (2019). These countries are home to the highest proportion of refugees in the world. World Economic Forum. https://www.weforum.org/agenda/2019/03/mena-countries-in-the-middleeast-have-the-highest-proportion-of-refugees-in-the-world/

World Health Organization. (2010). How health systems can address health inequities linked to migration and ethnicity. WHO Regional Office for Europe.

Yasmin, N. A. (2019). Opportunities for refugee access to work in Malaysia. Institute of

Strategic and International Studies (ISIS) Malaysia, 1-19. https://www.jstor.org/stable/resrep19605

Yunus, R. M., Azme, N., Chen, X. W., Badlishah-Sham, S. F., Miptah, H.N., \& Azraai,

A. M. (2021). The need to map existing health care services for refugees in Malaysia. J Glob Health, 11, 03024. doi:10.7189/jogh.11.03024 